\title{
Localization and Developmental Expression Patterns of the Neuronal K-Cl Cotransporter (KCC2) in the Rat Retina
}

\author{
Tania Q. Vu, ${ }^{1}$ John A. Payne, ${ }^{2}$ and David R. Copenhagen ${ }^{1}$ \\ ${ }^{1}$ Departments of Ophthalmology and Physiology, University of California, School of Medicine, San Francisco, California \\ 94143, and 2Department of Human Physiology, University of California, School of Medicine, Davis, California 95616
}

The processing of signals by integrative neurons in the retina and CNS relies strongly on inhibitory synaptic inputs, principally from GABAergic and glycinergic neurons that serve primarily to hyperpolarize postsynaptic neurons. Recent evidence indicates that the neuron-specific $\mathrm{K}-\mathrm{Cl}$ cotransporter 2 (KCC2) is the major chloride extrusion system permitting hyperpolarizing inhibitory responses. It has been hypothesized that depolarizing GABA responses observed in immature neurons are converted to hyperpolarizing responses in large part by the expression of KCC2 during the second week of postnatal development. The cell-specific localization and developmental expression of KCC2 protein have been examined in relatively few neural tissues and have never been studied in retina, of which much is known physiologically and morphologically about inhibitory synaptic circuits. We examined the localization of KCC2 in adult rat retina with immunohistochemical techniques and determined the time course of its postnatal expression. KCC2 ex- pression was localized in horizontal cells, bipolar cells, amacrine cells, and, most likely, ganglion cells, all of which are known to express GABA receptor subtypes. Developmentally, KCC2 expression in the retina increased gradually from postnatal day 1 (P1) until P14 in the inner retina, whereas expression was delayed in the outer plexiform layer until P7 but reached its adult level by P14. These data support the hypothesis that the function of KCC2 is intimately involved in GABAergic synaptic processing. Furthermore, the delayed temporal expression of KCC2 in the outer plexiform layer indicates that GABAergic function may be differentially regulated in retina during postnatal development and that GABA may produce depolarizing responses in the outer plexiform layer at times when it generates hyperpolarizing responses in the inner plexiform layer.

Key words: potassium chloride cotransporter; GABA receptors; chloride gradient; retinal development; synaptogenesis; GABAergic excitation; synaptic inhibition; synaptic excitation
GABA is the predominant inhibitory transmitter in the nervous system, causing membrane hyperpolarization via increases in chloride conductances. Early in postnatal development, however, GABA is excitatory. Both exogenously applied and synaptically released GABA produce depolarizing membrane potentials and resultant increases in intracellular $\mathrm{Ca}^{2+}$ in neurons in a variety of systems, including the retina, neocortex, hippocampus, and spinal cord [rat (Cherubini et al., 1991; Luhmann and Prince, 1991; Yuste and Katz, 1991; Zhang et al., 1991); mouse (Bahring et al., 1994); rabbit (Huang and Redburn, 1996); Xenopus (Rohrbough and Spitzer, 1996); and ferret (Fischer et al., 1998)]. This excitatory effect of GABA is short-lived, generally shifting to inhibitory action after the first postnatal week, and may participate in synaptic development by regulating calcium-dependent processes (Yuste and Katz, 1991; Owens et al., 1996).

Despite the growing number of reports demonstrating GABA's depolarizing effect, little is known about the mechanism of this phenomenon or its transition to inhibitory action. Because

\footnotetext{
Received Sept. 1, 1999; revised Nov. 19, 1999; accepted Nov. 24, 1999.

This work was supported by National Institutes of Health grants to D.R.C. and to J.A.P. Further support was provided by a National Institutes of Health core grant [Department of Ophthalmology, University of California, San Francisco (UCSF)], by University of California Davis Health System Research funds (J.A.P.), by That Man May See (UCSF), and by Research to Prevent Blindness (UCSF). We thank René Rentería and Michael Silver for critical reading of this manuscript, David Bredt for providing the PSD95 antibody, David Sretavan for use of the deconvolution microscope, and Michael Silver for discussion of image-processing techniques.

Correspondence should be addressed to Dr. Tania Vu, Departments of Ophthalmology and Physiology, Room K140, Box 0730, 10 Kirkham Street, University of California, San Francisco, San Francisco, CA 94143. E-mail: taniavu@itsa.ucsf.edu. Copyright (C) 2000 Society for Neuroscience $0270-6474 / 00 / 201414-10 \$ 15.00 / 0$
}

GABA-evoked depolarization requires an outwardly directed chloride flux, it has been hypothesized that young neurons maintain elevated levels of intracellular chloride that decrease to adult levels as a more effective chloride extrusion system develops with maturation. In support for this idea, chloride-loading experiments show that chloride extrusion is inefficient in young rat cortical neurons (Luhmann and Prince, 1991). In addition, chloride is passively distributed across young hippocampal neurons but exhibits an equilibrium potential more negative than the resting potential in older neurons (Zhang et al., 1991).

In adult mammalian neurons, active chloride extrusion is achieved via the obligatory coupled transport of potassium and chloride ions via an electroneutral $\mathrm{K}-\mathrm{Cl}$ cotransporter (Thompson et al., 1988; Thompson and Gahwiler, 1989; AlvarezLeefmans, 1990). To date, four distinct isoforms of the $\mathrm{K}-\mathrm{Cl}$ cotransporter (KCC) have been cloned [KCC1 (Gillen et al., 1996); KCC2 (Payne et al., 1996); KCC3 (Hiki et al., 1999); and KCC3 and KCC4 (Mount et al., 1999)]. Of these four KCC isoforms, only $\mathrm{KCC} 2$ is exclusively found in neurons and exhibits a high transport affinity for external $\mathrm{K}^{+}$, indicating that it is the likely isoform involved in neuronal $\mathrm{Cl}^{-}$extrusion (Payne et al., 1996; Payne, 1997; Williams et al., 1999). Recently, Rivera et al. (1999) have shown that a reduction in KCC2 expression correlates with a decrease in the GABAergic driving force. Moreover, single-cell PCR with hippocampal neurons revealed that the level of KCC2 was higher than that of KCC1 and followed a temporal expression pattern that correlates with GABA-mediated shifts in reversal potential. These observations strongly support the hypothesis that KCC2 functions as the major active chloride extru- 
sion system responsible for the GABAergic developmental shift in polarity.

The retina is a physiologically accessible tissue about which there is extensive knowledge of neurotransmitter receptor localization and some knowledge of the developmental time course of its inhibitory circuitry. A study of the localization and developmental regulation of $\mathrm{KCC} 2$ in the retina would be a way to test further the hypothesis that $\mathrm{KCC} 2$ is likely to play a role in inhibitory neurotransmission and would also be informative as to the temporal development of inhibitory circuits. Accordingly, we investigated the cell-specific localization and the postnatal expression patterns of $\mathrm{KCC} 2$ in the retina.

\section{MATERIALS AND METHODS}

Animals and tissue preparation. Long-Evans rats at ages postnatal day 1 (P1)- P47 (Simonsen, Gilroy, CA) and adult Royal College of Surgeons (RCS) rats (from Matthew LaVail's colony at the University of California, San Francisco) were studied. All procedures were performed in accordance with National Institutes of Health guidelines and were approved by the Committee on Animal Research, University of California, San Francisco. To ensure uniformity in the developmental studies, we used the retinas of littermates, fixed tissue using identical protocols, and performed immunohistochemical procedures in parallel for retinal sections of different developmental ages. Rats were killed by $\mathrm{CO}_{2}$ asphyxiation, followed by cervical dislocation; very young rats (P1-P5) were killed by decapitation. After enucleation, the corneas were perforated with a razor blade, and entire eyes were fixed by submersion in $4 \%(\mathrm{w} / \mathrm{v})$ paraformaldehyde in $0.1 \mathrm{M} \mathrm{PBS}$ at $4^{\circ} \mathrm{C}$. Long fixation times may diminish the likelihood of antibody penetration and the integrity of the antigen; fixation times of 30 and $90 \mathrm{~min}$ yielded a satisfactory compromise between effective tissue preservation and antibody binding. After rinsing in $0.1 \mathrm{M}$ PBS (twice for $10 \mathrm{~min}$ each), the eyes were cryoprotected by immersion in $20 \%$ sucrose PBS at $4^{\circ} \mathrm{C}$. On the following day, the eyes were embedded in ornithine carbamyl transferase and flash frozen on dry ice. Vertical sections, $10-20 \mu \mathrm{m}$ thick, were cut on a cryostat, collected on Super-frost Plus slides (Fisher Scientific, Pittsburgh, PA), and stored frozen at $-20^{\circ} \mathrm{C}$ until use.

Immunohistochemistry. The rabbit polyclonal antibody used in this study was raised against the neuron-specific form of the KCC2 (Williams et al., 1999). This antibody is directed toward a 112 amino acid fusion protein and was raised in rabbit. This antibody stains differentiated neurons only and displays broad cross-reactivity among vertebrates (Williams et al., 1999). The antibody can be used for both Western blot analysis and immunohistochemistry (Williams et al., 1999). Monoclonal antibodies to the following proteins were coapplied with the KCC2 antibody in double-labeling experiments: postsynaptic density 95 (PSD95) (a gift from David Bredt, University of California, San Francisco), Thy-1 (MAB 1406; Chemicon, Temecula, CA), calbindin-D (CL300; Sigma, St. Louis, MO), PKC ( $\alpha, \beta$, and $\gamma$ isoforms; clone MC5; Santa Cruz Biotechnology, Santa Cruz, CA), and synaptic vesicle 2 (SV2) (developed by Kathleen Buckley and obtained from the Developmental Studies Hybridoma Bank, University of Iowa, Department of Biological Sciences). For detection of primary antibodies, both goat anti-rabbit indocarbocyanine (Cy3) IgG and donkey anti-mouse FITC IgG $(\mathrm{H}+\mathrm{L}$ chains; Jackson ImmunoResearch, West Grove, PA) secondary antibodies were used. Primary and secondary antibodies were diluted in blocking solution at the following concentrations: KCC2 (1:100), Thy-1 (1:200), Calbindin-D (1:200), PSD95 (1:200), PKC (1:100), SV2 (1:100), Cy3 (1:500), and FITC (1:500).

Retinal sections were washed in $0.1 \mathrm{M}$ PBS (three times for $5 \mathrm{~min}$ each), blocked with solution containing $2 \%$ normal goat serum, $0.1 \%$ bovine serum albumin, and $0.1 \%$ Triton X-100 in PBS for $1 \mathrm{hr}$ at room temperature, and then incubated with the primary antibody against $\mathrm{KCC} 2$ in blocking solution at $4^{\circ} \mathrm{C}$ for $15-17 \mathrm{hr}$. After incubation, the sections were washed in PBS (three times for $5 \mathrm{~min}$ each). Sections were incubated in the secondary antibody in blocking solution for $1.5-2 \mathrm{hr}$ at room temperature, washed in PBS (three times for 5 min each) and $\mathrm{dd}_{2} \mathrm{O}$ (twice for $10 \mathrm{~min}$ each), and coverslipped with Elvanol. For double-labeling experiments, a mixture of primary antibodies was applied, followed by a mixture of secondary antibodies.

A concentration series was performed with the $\mathrm{KCC} 2$ antibody to determine the appropriate dilutions to yield optimal signal to noise.
Negative controls were performed for every set of experiments by omitting the primary antibody. Additional controls were used in doublelabeling experiments; incubations of one primary antibody followed by the nontarget secondary antibody were done to ensure that crossreactions did not occur between the secondary antibody and the nontarget primary antibody. With the exception of faint staining caused by the nonspecific affinity of secondary antibodies to photoreceptor outer segments and, in rare cases, blood vessels, these controls yielded dark images.

Western blots. Rat retinas were isolated and frozen in liquid nitrogen. Membranes were prepared by differential centrifugation as described previously (Williams et al., 1999). After protein concentration determination using a Micro-BCA kit (Pierce, Rockford, IL), membrane proteins (100 $\mu \mathrm{g}$ per sample) were resolved by SDS PAGE using a $7.5 \%$ Tricine gel system as described previously (Williams et al., 1999). No detergents other than SDS were used in the Western analysis. Gels were electrophoretically transferred to polyvinylidene difluoride (PVDF) membranes (Immobilon P; Millipore, Bedford, MA) in transfer buffer (192 mm glycine, $25 \mathrm{~mm}$ Tris-Cl, $\mathrm{pH} 8.3$, and $15 \%$ methanol) for $\geq 5 \mathrm{hr}$ at 50 $\mathrm{V}$ using a Bio-Rad Trans-Blot tank apparatus (Hercules, CA). PVDFbound protein was visualized by staining with Coomassie brilliant blue R-250. The PVDF membrane was blocked in PBS-milk (7\% nonfat dry milk and $0.1 \%$ Tween 20 in PBS, pH 7.4) for $1 \mathrm{hr}$ and then incubated in PBS-milk with affinity-purified polyclonal anti-KCC2 antibodies either overnight at $4^{\circ} \mathrm{C}$ or $2 \mathrm{hr}$ at $24^{\circ} \mathrm{C}$. After three 10 min washes in PBS-milk, the PVDF membrane was incubated with secondary antibody (horseradish peroxidase-conjugated goat anti-rabbit IgG; Zymed, San Francisco, $\mathrm{CA})$ for $2 \mathrm{hr}$ at $24^{\circ} \mathrm{C}$ in PBS-milk. After three washes in PBS with $0.1 \%$ Tween 20, bound antibody was detected using an enhanced chemiluminescence assay (NEN, Boston, MA).

Detection and image processing. Immunofluorescent and bright-field retinal sections were viewed using $20 \times$ air and $40 \times$ oil objectives on a Zeiss Axiophot microscope equipped with both Nomarski optics and $\mathrm{Cy} 3$ and FITC filters for fluorescence. Images were captured on slide film (Kodak Ektachrome Elite 400) at fixed exposure times of 0.4, 2, or $60 \mathrm{sec}$ and digitized using a slide scanner (Sprint Scanner 35 Plus). For higher resolution viewing, immunofluorescent images were collected on a deconvolution microscope (Delta-Vision SA3.1) using a $20 \times$ air objective or a confocal laser-scanning microscope (Bio-Rad MRC 1024) using $20 \times$ air and $60 \times$ oil objectives. For double-labeled slides, confocal laser scans were collected sequentially for $\mathrm{Cy} 3$ and FITC label to prevent spectral bleed through; under these conditions either the yellow or the blue line of the laser illuminated the sample during a scan. To ensure that FITC illumination did not significantly excite Cy3 label (and vice versa), we examined fluorescence during FITC illumination for Cy3-labeled sections (and vice versa) using both the light and deconvolution microscopes. Under these conditions fluorescence was dark or negligible.

Adobe Photoshop (version 5) was used to adjust the brightness and contrast levels of digitized images and to produce pseudocolor-overlay images. Simple quantitative analysis was performed using the public domain NIH Image program (version 1.61) that is available on the Internet at http://rsb.info.nih.gov/nih-image. Care was taken to ensure that parameters for contrast and brightness were identical for comparisons among tissue sections of different developmental ages and for comparisons between test and negative controls.

Colocalization of two antibody stains was determined by the degree of overlap of superimposed pseudocolor images of double-labeled retinal tissue. For doubled-labeled retinal sections using KCC2 and calbindin antibodies, colocalization was also determined using a shuffled condition algorithm that follows that used by Silver and Stryker (M. A. Silver, personal communication). This algorithm expresses the degree of correlation between KCC2 and calbindin stains using pixel-by-pixel multiplication of a retinal section that was doubled labeled for $\mathrm{KCC} 2$ and calbindin (see Fig. $3 A, B, E$ ). Because multiplication between even two random images can yield some amount of random correlation, a measure of this background was determined by multiplication of the original calbindin-labeled retinal section and a "random" KCC2-labeled retinal section (see Fig. $3 F$ ). The random image we selected was a KCC2-labeled retinal section that was positioned at $4 \mu \mathrm{m}$ in the $z$-plane above the original doubled-labeled retinal section (see Fig. $3 D$ ). At this distance in the $z$-plane, the KCC2-labeled optical section yields a pattern of KCC2 fluorescence that differs from that seen in the original section (see Fig. $3 A, D$, compare the KCC2-labeled cellular processes and somata) but preserves the general orientation of the original KCC2 section. The final amount of correlation between $\mathrm{KCC} 2$ and calbindin stains is obtained by subtracting the image containing the amount of background correlation 
Figure 1. KCC2 immunoreactivity is restricted to the OPL, INL, and IPL in rat retina. Photomicrographs of vertical cryostat sections through Long-Evans (LE) rat retina. $A$, Middle, Confocal fluorescence micrograph of KCC2 immunolabeling. Left, Bright-field image from the field of view used to illustrate the retinal layers. Right, Control (no primary antibody). $B$, Fluorescence confocal micrograph image of $\mathrm{KCC} 2$ immunoreactivity at higher power. White arrows point to immunostained processes emanating from bipolar cell somata. Asterisks mark KCC2-positive amacrine cell somata. The OPL (not labeled) lies at the junction between the ONL and INL. Scale bars: $A, 57 \mu \mathrm{m} ; B, 31 \mu \mathrm{m}$.
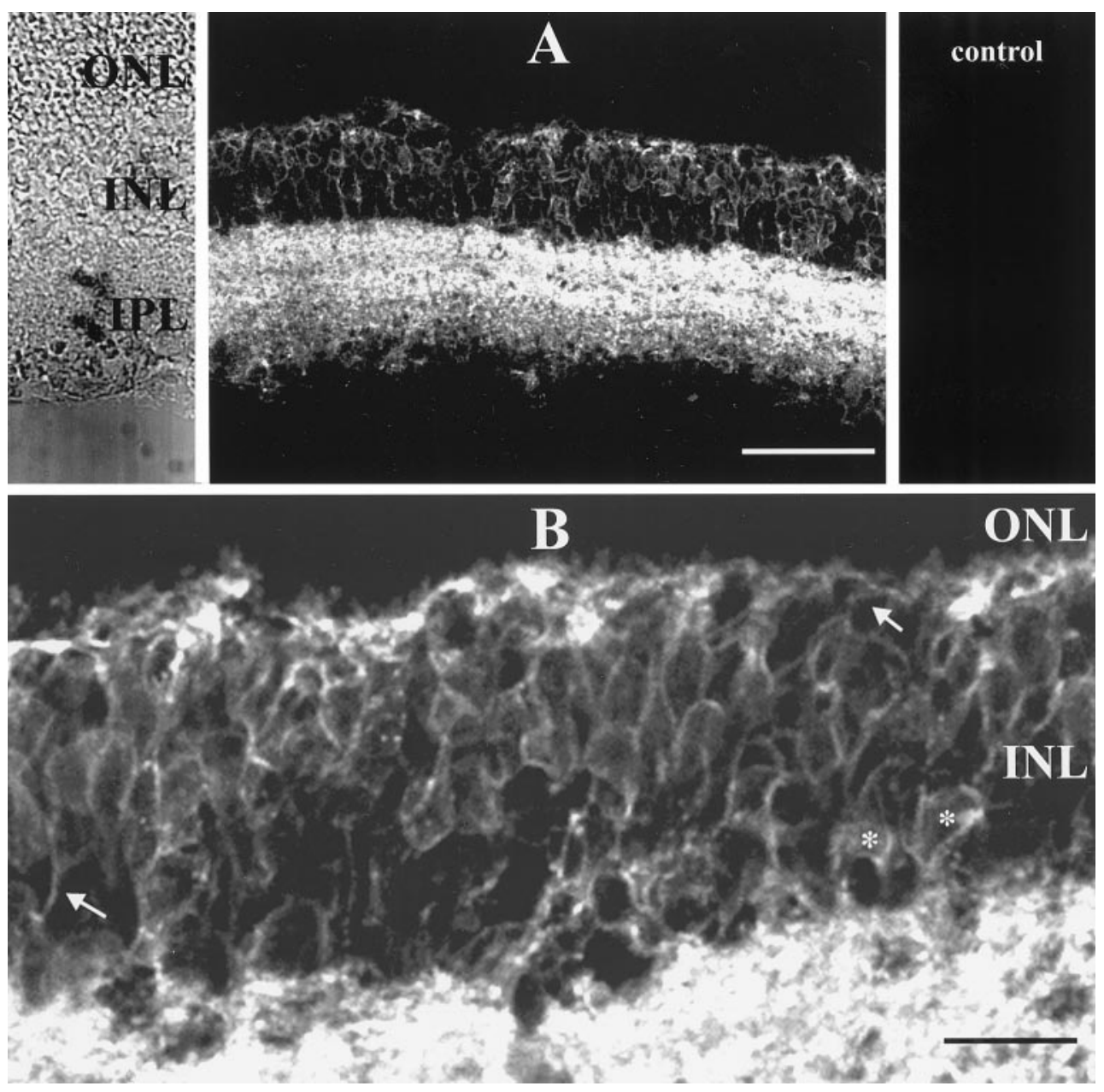

(see Fig. $3 F$ ) from the product of the $\mathrm{KCC} 2$ and calbindin images in the $z=0$ plane (see Fig. $3 E$ ). This result (see Fig. $3 G$ ) is expressed in gray scale, with darker pixel values indicating a higher degree of correlation.

\section{RESULTS}

\section{General distribution of $\mathrm{KCC} 2$ in the adult retina}

Vertical retinal sections labeled with the KCC2 antibody show that the $\mathrm{K}-\mathrm{Cl}$ cotransporter is abundantly expressed in the adult rat retina and is confined to specific retinal laminae (Fig. $1 A$ ). In the outer plexiform layer (OPL), at the juncture between the outer nuclear layer (ONL) and the inner nuclear layer (INL), $\mathrm{KCC} 2$ is distributed as bright puncta in a background of a more faintly stained, diffuse pattern of immunoreactivity (Fig. 1). $\mathrm{KCC} 2$ is also contained on the somal membranes and the ascending and descending processes of select populations of neurons residing in the INL (Fig. $1 B$, white arrows). Diffuse staining is seen across the full extent of the inner plexiform layer (IPL), with more intense bands observed within two sublaminae located in the distal and central portion of the IPL. An absence of KCC2 immunoreactivity in the ONL indicates that photoreceptors do not express the cotransporter on their somal membranes, although in a few retinal sections we detected very faint staining in the ONL, indicating that trace levels of KCC2 could be present.

\section{Localization of KCC2 in the outer plexiform layer of the adult retina}

We performed a series of double-labeling experiments to localize KCC2 to single neuronal types in the outer retina. Figure 2, $A$ and
$B$, shows a vertical section of retina that was double-labeled with antibodies to KCC2 (Fig. 2B, red) and PSD95 (Fig. 2A, green), a synaptic protein belonging to the family of ion channel-clustering molecules. In the mammalian retina, immunolabeling with the antibody to PSD95 shows labeling that is confined to presynaptic sites at the photoreceptor synapse and stains entire axon terminals of rod spherules and cone pedicles (Koulen et al., 1998). In Figure $2 C$, the composite overlay of KCC2 and PSD95 immunoreactivity shows that $\mathrm{KCC} 2$ is substantially confined to postsynaptic regions of the OPL. In some areas of the tissue, it was possible to see some small amount of overlap between the two labels in the OPL. This could be caused by out-of-focus fluorescence, although the possibility that small amounts of $\mathrm{KCC} 2$ could be present at the very basal portions of photoreceptor terminals cannot be completely precluded.

Further evidence of the exclusion of KCC2 from photoreceptor terminals is shown in Figure $2 D-F$ that contains sections of retina double-labeled with the antibodies for KCC2 (Fig. 2E, red) and SV2 (Fig. 2D, green). SV2, a synaptic vesicle membrane protein present in the CNS and peripheral nervous system (Buckley and Kelly, 1985), is localized exclusively to photoreceptor terminals at the OPL in the rodent retina (Rich et al., 1997). An absence of overlapping staining in the false color overlay of KCC2 and SV2 (Fig. $2 F$ ) indicates that the KCC2 immunoreactivity seen at the OPL is excluded from and proximal to cone pedicles and rod spherules. In the IPL, there is considerable evidence of substantial overlap of the KCC2 and SV2 images. The results of these 

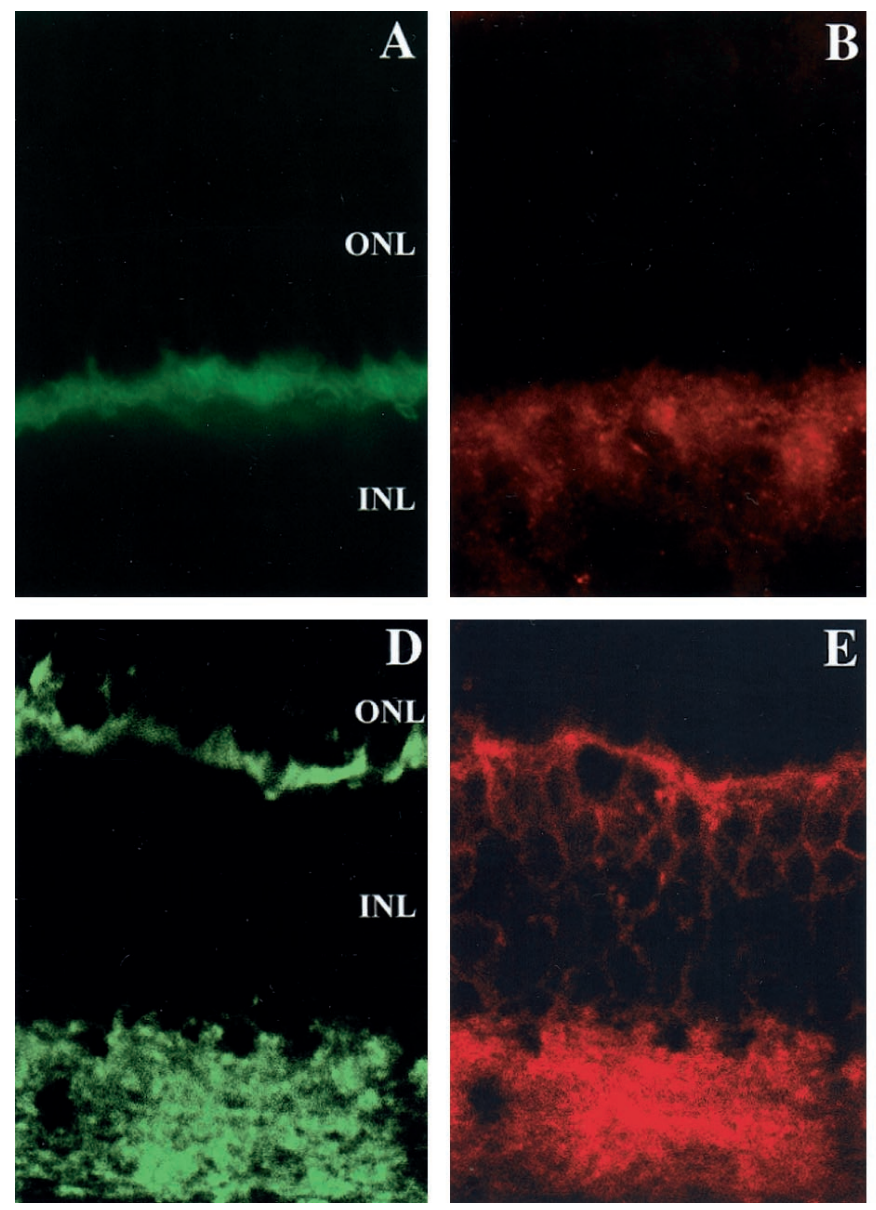
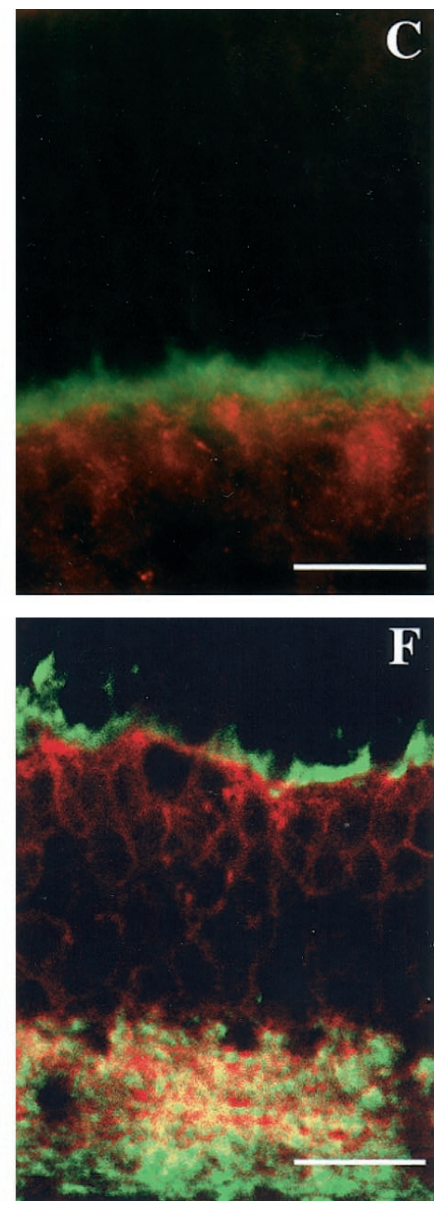

Figure 2. KCC2 immunoreactivity does not colocalize with immunolabels for rod and cone synaptic terminals. $A-C$, Fluorescence micrographs taken on a deconvolution microscope of colabeling of the same vertical section of RCS rat retina with PSD95 ( $A$; green) and $\mathrm{KCC} 2(B$; red $)$ antibodies. $C$, The pseudocolor overlay of $A$ and $B$. The PSD95 staining overlaps minimally with the KCC2 staining. $D-F$, Fluorescence confocal micrographs of colabeling of a vertical section of LE rat retina colabeled with SV2 (D; green) and KCC2 (E; red). $F$, The pseudocolor overlay of $D$ and $E$. Substantial overlap of SV2 and $\mathrm{KCC} 2$ is apparent in the IPL, but little overlap exists in the OPL. Scale bars: $A-C, 17 \mu \mathrm{m} ; D-F, 18 \mu \mathrm{m}$. double-labeling experiments using both SV2 and PSD95 labels are consistent with the conclusion that $\mathrm{KCC} 2$ is confined primarily to postsynaptic neurons in the OPL.

KCC2 follows a distribution at the OPL that appears as intense areas of KCC2 immunoreactivity superimposed on less intense and more diffusely immunolabeled cellular processes in the plexiform layer (see Figs. 1B, 4). This dual pattern of labeling could be caused by two different populations of neurons such as horizontal cells and bipolar cells. To test this hypothesis, we performed double-labeling experiments with antibodies to KCC2 and to calbindin, a calcium-binding protein. The rat retina has a single population of horizontal cells, the B-type axon-bearing horizontal cells, that have somata that lie in the outer region of the INL and make synaptic contact with photoreceptors in the OPL (Peichl and Gonzaalez-Soriano, 1994). In the rat outer retina, the calbindin antibody specifically stains the somata and processes of these axon-bearing horizontal cells (Pasteels et al., 1990; Peichl and Gonzaalez-Soriano, 1994). Figure 3 shows a pseudocolor overlay for a retinal tissue section double-labeled for KCC2 (Fig. 3A) and calbindin (Fig. 3B). The pattern of overlap of calbindin stain (green) with some of the KCC2 stain (red) in the OPL (Fig. 3C) suggests that horizontal cells express KCC2 in their processes but not in their somata. To confirm this further, colocalization was examined by a correlation between the pixel values in Figure $3, A$ (KCC2 stain) and $B$ (calbindin stain). The degree of colocalization between the KCC2 and calbindin stains is shown as a correlation in Figure $3 E$ (see Materials and Methods) and is expressed by multiplication of the KCC2 and calbindin sections (Fig. 3A,B). Background noise, caused by random corre- lation between the two labels, is shown in Figure $3 F$. The difference between Figure 3, $E$ and $F$, yields the resulting gray scale pattern of correlation shown in Figure $3 G$; dark pixel values indicate areas of higher correlation. The similarity among the calbindin stain (Fig. $3 B$ ), the pseudocolor overlay (Fig. $3 C$ ), and the computed pixel correlation (Fig. 3G) strongly supports the idea that KCC2 is expressed in horizontal cell processes.

Figure $3 C$ also shows that some areas of KCC2 stain do not overlap with the calbindin stain, indicating that structures in addition to horizontal cells contain KCC2. This is consistent with Figures $1 B, 2 E$, and $3 A$ that show examples of KCC2 label on the processes of presumptive bipolar cells whose immunoreactive somata are situated in the INL (see below).

In summary, these results show that $\mathrm{KCC} 2$ is localized to postsynaptic cells in the outer plexiform layer and is expressed along the processes of horizontal cells and bipolar cells.

\section{Localization of KCC2 in the inner nuclear layer of the adult retina}

Figure 4 shows that KCC2 is distributed at the somal membrane of cells that are positioned in the outer to central INL. In addition to staining on their somata, these cells have KCC2 in their ascending and descending processes (see Figs. 1B, 2E). Because of the bipolar form of these neurons and the lack of colocalization of KCC2 and calbindin immunoreactivity in putative horizontal cell somata, the stained INL neurons are likely to be bipolar cells.

In the rat retina, there are nine types of cone bipolar cells and a single type of rod bipolar cell. These different classes of bipolar 
Figure 3. Pseudocolor overlay and pixel-by-pixel correlation of calbindin and immunoimages reveal significant colocalization in horizontal cell processes but not in their somata. $A-C$, Fluorescence micrographs of a vertical section of LE rat retina double-labeled for $\operatorname{KCC} 2(A ; r e d)$ and calbindin $(B$; green). $C$, The pseudocolor overlay of $A$ and $B$. Substantial overlap exists in the OPL, whereas little overlap exists between $\mathrm{KCC} 2$ and calbindin staining in horizontal cell somata. Note the areas of KCC2-positive processes ascending from bipolar cell somata in the INL that do not overlap with calbindin stain. $D$, A fluorescence micrograph taken at $4 \mu \mathrm{m}$ above the focal plane of the images in $A$ and $B$. This image is used to account for background correlation (shown in F). E, The correlation of calbindin and KCC2 stains computed by multiplication of the calbindin-positive image $(B)$ with the KCC2-positive image $(A)$ on a pixel-by-pixel basis. $F$, The result of pixel multiplication of the calbindin-positive image $(B)$ and the KCC2-positive image taken at $4 \mu \mathrm{m}$ above the focal plane of the original images $(D)$. This image serves as a control and quantifies the amount of background. $G$, The resulting image obtained by subtracting the out-of-plane image $(F)$ from the in-plane image $(E)$. This resultant image represents a more accurate rendition of the staining colocalized within the same plane of focus. Note that the pattern of overlap in $C$ is similar to that seen in G. Cal, Calbindin. Scale bar, $29 \mu \mathrm{m}$.
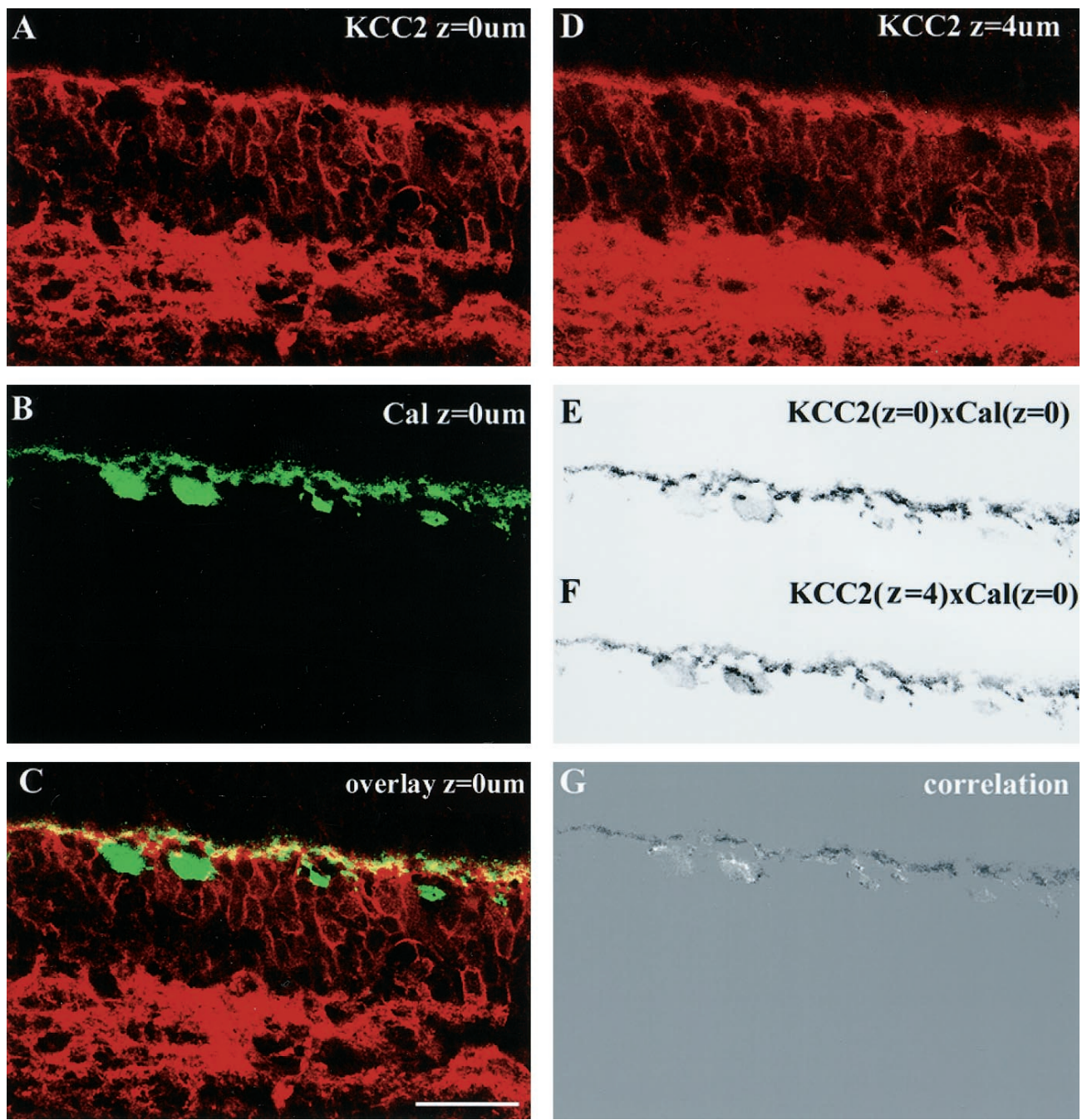

cells can be morphologically distinguished by their dendritic arborization, the size and location of their somata, and the stratification of their axon terminals in the IPL (Euler and Wässle, 1995). Rod bipolar cell somata lie close to the OPL, whereas the nine types of cone bipolar cells have somata that are positioned at varying levels from the distal to central portion of the INL. When a single class of bipolar cell is labeled, a regular array is formed by cell somatas and processes across the field of view; this regularity can also be seen when two classes of bipolar cells are labeled (see Euler and Wässle, 1995). Because the KCC2-positive bipolar cells shown in Figure 4 lack this spatial regularity, $\mathrm{KCC} 2$ is contained in three or more populations of bipolar cell types. It is possible that rod bipolar somata express KCC2 because cells with relatively large somata positioned near the distal portion of the INL were labeled (Wässle et al., 1991; Euler and Wässle, 1995), and double-labeling experiments using anti-PKC confirm this (data not shown). The varied sizes and positions of KCC2-positive bipolar cell somata seen in the central portions of the IPL and the lack of spatial regularity (see above) indicate that KCC2 is widely distributed among different classes of cone bipolar cells and present in at least two classes of cone bipolar cells.

In some instances, immunoreactive somata of presumptive amacrine cells were observed in the proximal half of the INL (Figs. 1B, 4, asterisks). One type of interplexiform layer cell has been identified in the rat; this interplexiform cell has a soma positioned in the INL close to the border of the IPL and sends ascending processes through the INL into the OPL (Perry and Walker, 1980). Because we never observed long ascending processes from these particular KCC2-positive somata, these cells were unlikely to be interplexiform layer cells but are more likely to be some type of amacrine cell.

\section{Localization of KCC2 in the inner plexiform layer of the adult retina}

The KCC2 antibody labels the IPL in a faint diffuse pattern, across its full extent, and in an intense punctate pattern, at two broadly labeled strata (Fig. 5B). These two immunofluorescent strata correspond to the On and Off sublaminae that, in mammals, are located at the central and distal half of the IPL, respectively (Wässle et al., 1991). The KCC2-positive descending processes of bipolar cells seen in the INL and the punctate nature of the labeled strata in the IPL, shown at higher magnification in Figure $4 A$, indicate that bipolar cell axon terminals make a large contribution to the observed immunofluorescence at the On and Off sublaminae (Wässle et al., 1991; Euler and Wässle, 1995). Rod-type On bipolar cells (BPCs) terminate exclusively at the most proximal stratum of the IPL, at the border of the IPL and the ganglion cell layer (GCL) (Wässle et al., 1991), and our double-labeling experiments with anti-PKC confirm that rod-type 

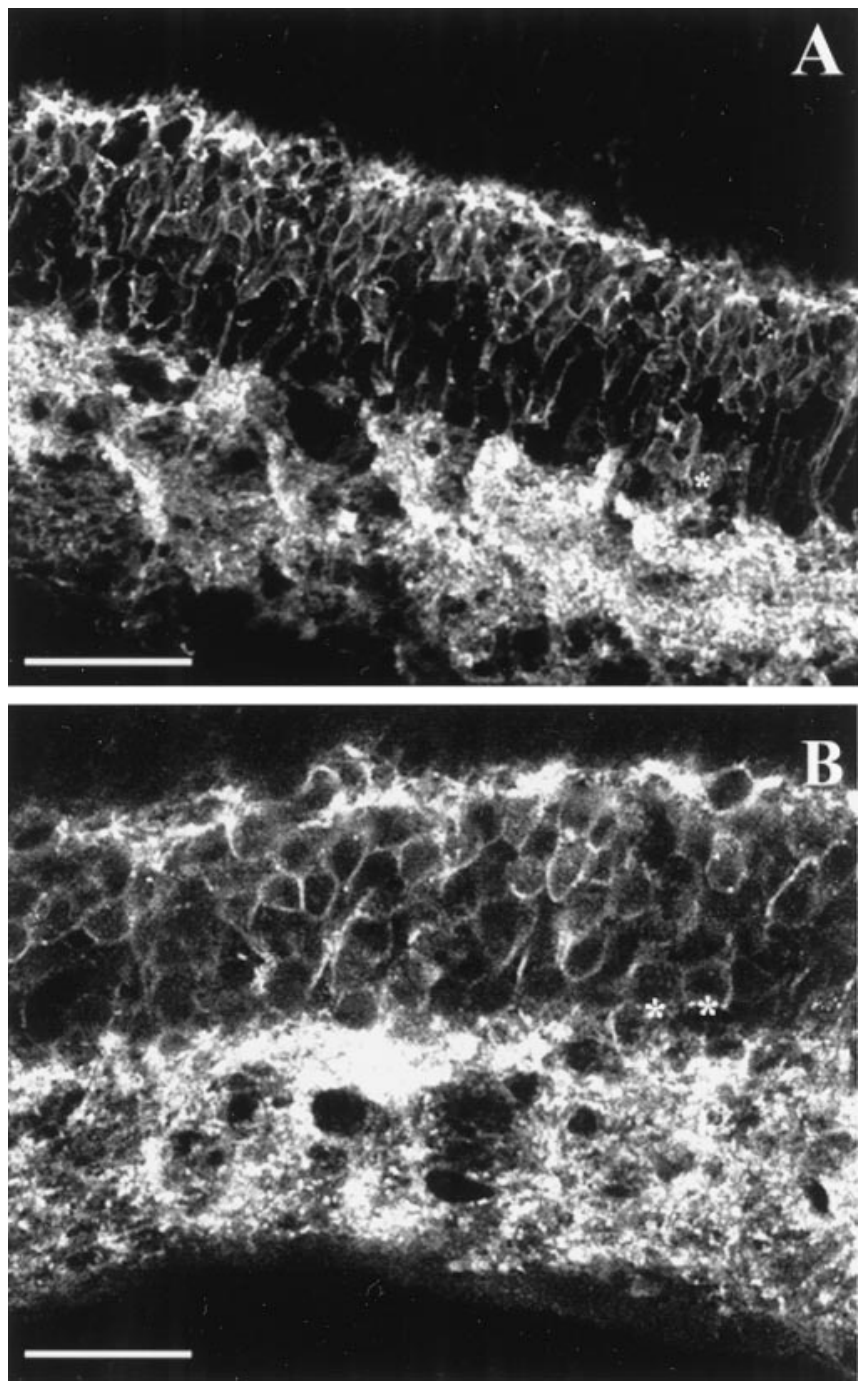

Figure 4. Fluorescence micrographs show KCC2-positive staining in several populations of bipolar cells and in amacrine cells. $A, B$, Low $(A)$ and higher $(B)$ power confocal fluorescence micrographs of vertical sections of LE rat retina immunolabeled for KCC2. KCC2 stains several populations of bipolar cell somata (see Results). Asterisks indicate KCC2positive membrane labeling of amacrine cell somata. Areas of intense and faint KCC2 stain label two different cellular structures in the OPL in $A$. Black arrows in $A$ point to the more intense $\mathrm{KCC} 2$ labeling of two strata in the IPL. Scale bars: $A, 40 \mu \mathrm{m} ; B, 21 \mu \mathrm{m}$.

On BPC axon terminals are KCC2 positive (data not shown). Thus, these results indicate that On rod bipolar cell terminals contain KCC2 and suggest that both On and Off cone bipolar cell terminals contain $\mathrm{KCC} 2$, contributing primarily to the intense punctate labeling seen in two strata of the IPL.

To explore the idea that ganglion cell (GC) dendrites may contribute to the observed pattern of diffuse KCC2 immunoreactivity, we tested for colocalization of $\mathrm{KCC} 2$ in GCs using double-labeling with antibodies for Thy-1, a neuronal cell-surface glycoprotein. Similar to previous reports, our results (Fig. 5A) show that immunostaining of rat retinal slices with Thy-1 produces a pattern of uniform and diffuse labeling throughout the IPL that is contributed from GC dendrites and possibly some amacrine cell dendrites; bright staining in the GCL is contributed from surface labeling of GC and displaced amacrine cell somata as well as GC axonal processes (Barnstable and Drager, 1984; Schmid et al., 1995; Taschenberger and Grantyn, 1995; Liu et al., 1996).

A comparison of KCC2 and Thy-1 immunoreactivity (Fig. $5 A, B)$ shows that both Thy- 1 and $\mathrm{KCC} 2$ antibodies produce similar and overlapping patterns of diffuse immunofluorescence spanning the entire IPL, providing evidence that is consistent with the idea that $\mathrm{KCC} 2$ is expressed in GC dendrites. These data also show that KCC2 is not contained in the somata and axonal processes of GCs. The false color overlay shown in Figure 5C illustrates a lack of overlap between KCC2 and Thy-1 immunoreactivity at the level of the GCL. Figure 5, bottom right, contains a composite of KCC2 labeling and a Nomarski image of a different retinal section further illustrating that KCC2 is absent from GC bodies.

Typically, stratified labeling such as that seen with labeling for receptor subunits (see Greferath et al., 1995) indicates that select populations of cells are immunoreactive. Thy-1 labels multiple subtypes of GCs that possess wide differences in their morphological as well as electrophysiological properties (Barres et al., 1988), and the uniform labeling we, as well as others, observe in the IPL (Fig. 5A) is consistent with this and suggests that KCC2 is expressed in several subtypes rather than in a specific subpopulation of GC dendrites.

\section{Expression of $\mathrm{KCC} 2$ in the developing retina}

During the first 2 weeks after birth, $\mathrm{KCC} 2$ expression is gradually upregulated in the retina. The level of KCC2 protein expression in whole retina was determined by Western blot analysis. Figure 6 shows that KCC2 protein was barely detectable at birth but increased over the following 2 weeks, reaching adult levels by approximately P14. An estimate of the increase in KCC2 protein expression, made by comparing the average pixel intensities over a region of constant area ( 0.08 inch $^{2}$ or 1813 pixels) in each blot lane, indicated that $\mathrm{KCC} 2$ protein expression had reached $25 \%$ of its adult intensity at $\mathrm{P} 3$ and $73 \%$ at $\mathrm{P} 7$.

Immunohistochemical labeling, which allows for spatial localization of $\mathrm{KCC} 2$ expression, reveals that $\mathrm{KCC} 2$ upregulation follows a differential time course in the inner and outer retina. Figure 7 shows a developmental series of retinal sections that were taken at identical exposure times and lighting conditions at approximately the same eccentricity in the peripheral retina. Each fluorescent image contains a Nomarski image of the same section and an intensity profile that represents the average of pixel intensities taken across the width of the fluorescent image. At P1, barely detectable levels of KCC2 are present in the inner retina at the proximal portion of the neuroblastoma layer. At P3, these levels become slightly more intense in the inner retina but are absent from the outer retina. Early in the second postnatal week at P10, diff use staining further increases at the IPL, and low levels of KCC2 are present in the OPL. This micrograph also shows that immunoreactivity is absent from the GCL. By the second week, KCC2 levels increased in both plexiform layers, and bipolar cells began to show KCC2 expression, starting first in their processes and than following in their somata. During the weeks after P14, as both the inner and outer plexiform layers increase in width, the distribution of KCC2 shifts from a uniform to a more punctate pattern (compare P14 and P32). Thus, KCC2 expression gradually increases during the first 2 weeks of postnatal development in the retina and follows two different time courses, commencing first in the inner retina and then following approximately a week later in the outer retina. 

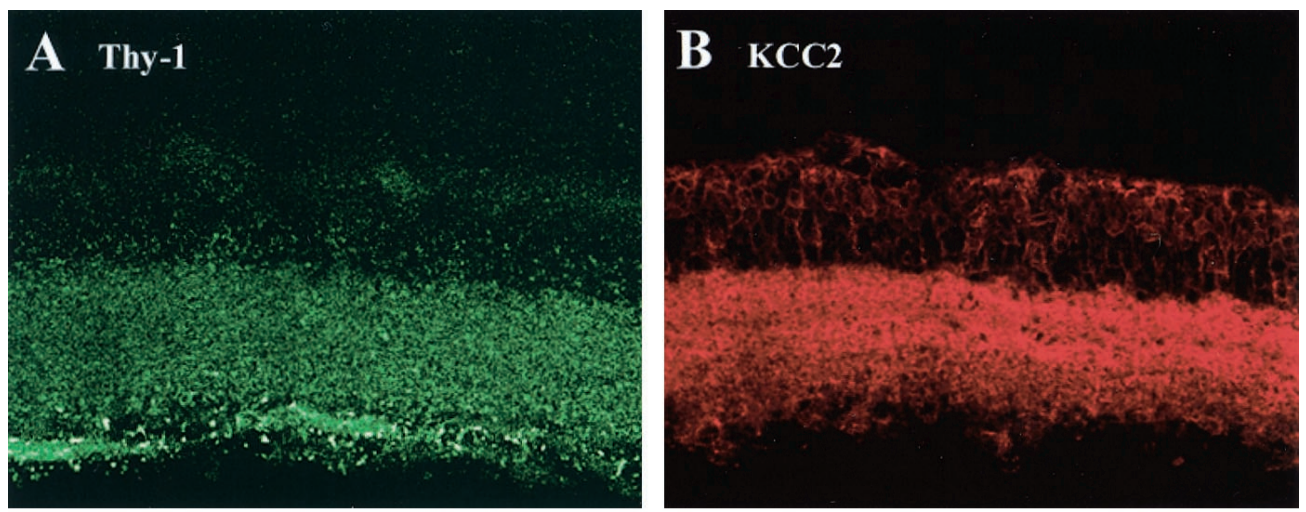

Figure 5. KCC2 immunoreactivity colocalizes with Thy-1 in the IPL but not in the GCL. $A-C$, Confocal fluorescence micrographs of the same vertical section of LE rat retina colabeled for Thy-1 $(A$; green $)$ and $\mathrm{KCC} 2(B$; red $)$. The pseudocolor overlay $(C)$ shows substantial overlap in the IPL but little overlap in the GCL. Bottom right, A superimposed fluorescence light microscope image of $\mathrm{KCC} 2$ immunoreactivity on a Nomarski image of the same section of the retina. It is readily apparent that staining is absent from cell bodies in the GCL. Scale bars: $A-C, 57$ $\mu \mathrm{m}$; bottom right, $25 \mu \mathrm{m}$.

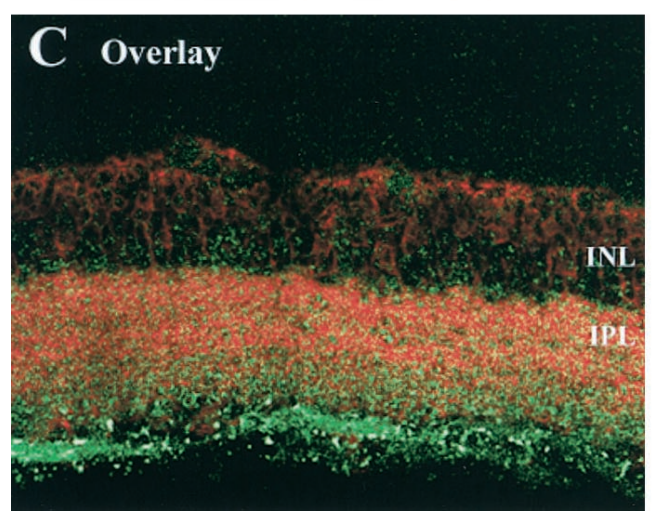

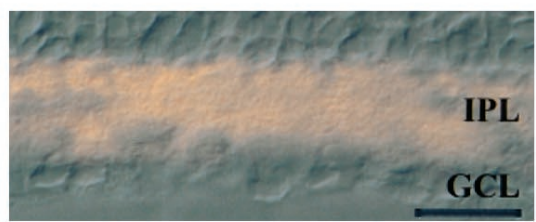

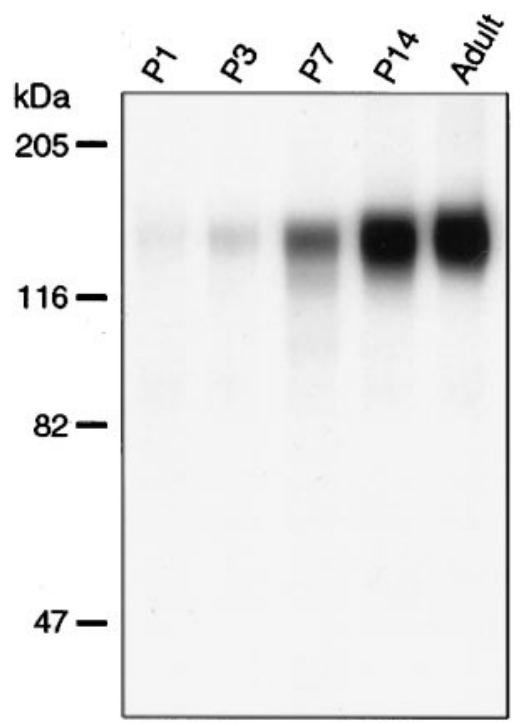

Figure 6. Western blot analysis of membranes from rat retinas at different developmental stages. Membrane were prepared from LE rat retinas (100 $\mu \mathrm{g} /$ lane $)$ and probed with anti-KCC2 antibodies (1:2000). KCC2 expression is barely detectable at P1 but rapidly increases after the first postnatal week, reaching adult levels by the end of the second postnatal week.

\section{DISCUSSION}

The neuron-specific $\mathrm{K}-\mathrm{Cl}$ cotransporter $\mathrm{KCC} 2$ has been shown to lower $E_{\mathrm{C} 1}$ below resting potentials to produce $\mathrm{GABA}_{\mathrm{A}^{-}}$ mediated hyperpolarizing potentials (Rivera et al., 1999). We report here that expression of $\mathrm{KCC} 2$ immunoreactivity in adult rat retina reveals colocalization on neurons known to express inhibitory receptor subunits. Also, our results show anisotropic spatial localization of KCC2 within neurons in which there is expression in dendrites but not in cell bodies, suggesting the existence of chloride gradients within individual cells and differential inhibitory receptor-mediated responses on these same cells. Postnatal developmental expression of KCC2 follows a gradual time course of upregulation that correlates with conversion of $\mathrm{GABA}_{\mathrm{A}}$-evoked excitatory responses to inhibitory ones. The delayed expression in the OPL relative to the IPL suggests that GABA could be generating depolarizing responses in bipolar cells at the same time it generates hyperpolarizing actions in ganglion and amacrine cells and thus might serve to promote synaptogenesis at the glutamatergic ribbon bipolar cell synapses, which are the last to form in the retina. In summary, these results provide strong support for KCC2's role in the mediation of GABAergic and glycinergic synaptic transmission in adult and maturing neural circuits.

\section{Localization of $\mathrm{KCC} 2$ in the adult retina}

$\mathrm{KCC} 2$ is strongly expressed in retina and exhibits localization to specific types of neurons. It is found in the processes of horizontal cells (HCs), on some types of amacrine cells, distributed among multiple classes of BPCs, and most likely in the dendrites of multiple classes of GCs. KCC2 is strongly expressed in BPC dendritic processes and axonal terminals and less intensely expressed in the somal membranes and along the ascending and descending processes of these cells. Punctate labeling of On and Off sublaminae in the IPL and double labeling with anti-PKC suggest that On rod type as well as both On and Off cone type $\mathrm{BPC}$ axons contain $\mathrm{KCC} 2$.

Besides the ever present confounding problem of nonspecific staining by the secondary antibodies, which we have minimized in this study, two principal artifacts must be considered: the crossreactivity of the anti-KCC2 antibodies with the other isoforms of the $\mathrm{K}-\mathrm{Cl}$ cotransporter and the reactivity with blood vessels. 

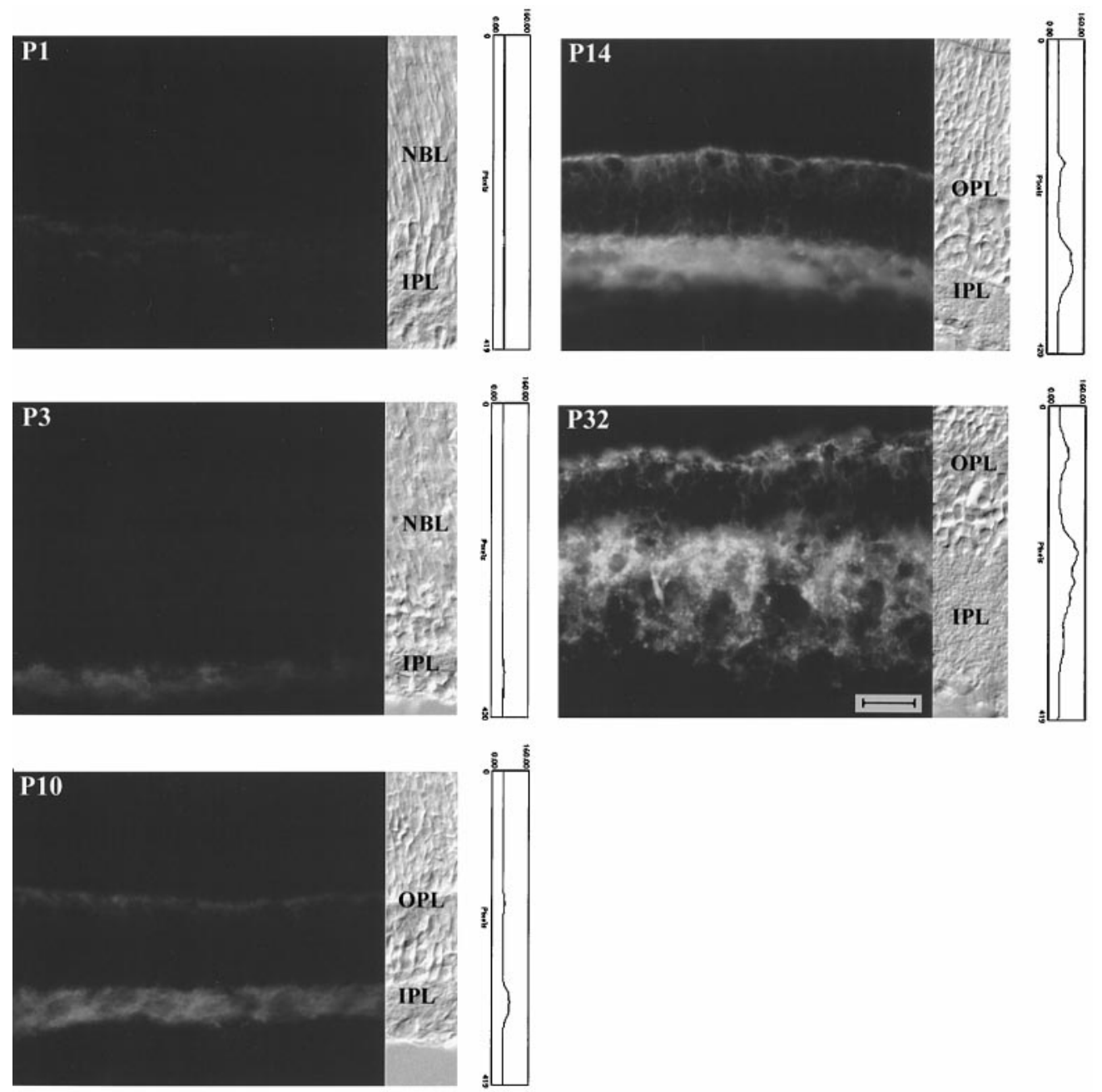

With regard to the first of these potential problems, the antiKCC2 antibodies were prepared against a portion of the sequence that is primarily unique to the KCC2 isoform (Payne et al., 1996; Payne, 1997). Approximately one-half of the amino acids of the $\mathrm{KCC} 2$ antigen do not align with those of the other $\mathrm{KCC}$ isoforms ( $\mathrm{KCC} 1, \mathrm{KCC} 3$, and $\mathrm{KCC} 4)$, and the remaining amino acids are poorly conserved between the isoforms ( $<32 \%$ identical). Furthermore, we have shown clearly that the anti-KCC2 antibodies do not cross-react with KCC1 protein (Williams et al., 1999). Thus, cross-reactivity with the other $\mathrm{KCC}$ isoforms is not a likely problem. With regard to reactivity with blood vessels, we found that unstained adjacent sections of retinal tissue were dark, lessening the likelihood of autofluorescent blood vessels contaminating the KCC2 patterns of immunoreactivity. In rare instances we did see some staining of blood vessels with secondary antibodies; however, the distinct twig-like patterns of blood vessel staining were readily distinguishable from those of KCC2.

\section{Colocalization of KCC2 and GABA and glycine receptors in the retina}

Recent evidence indicates that, in neurons, KCC2 colocalizes with anion-gated chloride-selective $\mathrm{GABA}_{\mathrm{A}}$ channels. In granule cells of rat cerebellum, KCC2 colocalizes with $\mathrm{GABA}_{\mathrm{A}}$ channel subunits $\left(\beta_{2} / \beta_{3}\right)$, and in cultured chick retinal amacrine cells, $\mathrm{KCC} 2$ is highly concentrated at areas of synaptic contact that are exclusively GABAergic (Williams et al., 1999). Our findings in rat retina are consistent with similar colocalization. We observe a correlation between retinal neurons containing $\mathrm{KCC} 2$ and neurons containing subunits not only for $\mathrm{GABA}_{\mathrm{A}}$ receptors but also for $\mathrm{GABA}_{\mathrm{C}}$ and glycinergic receptors.

In the rat retina, the glycinergic receptor $\alpha 1$ subunit is localized to the axon terminals of Off cone BPCs and to GC dendrites (Sassoè-Pognetto et al., 1994; Koulen et al., 1996). Correspondingly, we find that $\mathrm{KCC} 2$ immunoreactivity is strong in the distal part of the IPL where the synaptic connections between Off cells are made. Immunohistochemical studies show that nine different $\mathrm{GABA}_{\mathrm{A}}$ receptor subunits are predominantly localized to the IPL and that all classes of inner retinal neurons selectively express at least one of these subunits (Greferath et al., 1995; Wässle et al., 1998). In addition, in cone and rod BPCs, although $\mathrm{GABA}_{\mathrm{A}}$ receptor subunit distribution is strongest at the terminals, it is found also on the somata and dendrites of these cells (Wässle et al., 1998). Similarly, we find KCC2 is expressed on the somata and dendrites of BPCs, in amacrine cells, and most likely in GCs. In addition, the punctate nature of KCC2 label at the IPL (Fig. 4) is similar to that of labeling seen for clusters of $\mathrm{GABA}_{\mathrm{A}}$ and glycine receptors (Sassoè-Pognetto et al., 1994; Koulen et al., 1996), further supporting the idea of $\mathrm{KCC} 2$ and inhibitory receptor colocalization. Electrophysiological and immunohistochemical studies indicate that $\mathrm{GABA}_{\mathrm{C}}$ receptors are present in rod and cone BPCs (Euler et al., 1996; Wässle et al., 1998). KCC2 staining correlates with the $\mathrm{GABA}_{\mathrm{C}}$ in On and Off BPC terminals. Elec- 
trophysiological evidence indicates that $\mathrm{HCs}$ in rabbit and cat respond to GABA (Frumkes and Nelson, 1995; Blanco et al., 1996). In addition $\mathrm{GABA}_{\mathrm{A}}$ receptor immunoreactivity is found in rat HCs (Wässle et al., 1998), although it is absent in other mammalian species (Vardi et al., 1992). In summary, it seems that wherever KCC2 immunoreactivity is found, either $\mathrm{GABA}_{\mathrm{A}}$, $\mathrm{GABA}_{C}$, or glycine receptor immunoreactivity is found. Conversely, glycinergic subunit staining is not observed in cone and rod terminals. Also, although there is some evidence of selective $\mathrm{GABA}_{\mathrm{A}}$ subunit receptor staining in photoreceptors in rat, in general, immunohistochemical evidence of $\mathrm{GABA}_{\mathrm{A}}$ subunit staining in photoreceptors in mammalian retina is weak (Wässle et al., 1998). On the basis of this evidence, the general observation can be made that KCC2 absence from the photoreceptor terminal region of the OPL correlates to a lack of or low amounts of anion channel subunit populations in this part of the retina.

\section{Inhomogenous spatial distribution of $\mathrm{KCC} 2$ on individual neurons}

$\mathrm{KCC} 2$ is expressed on the processes of horizontal cells and, most probably, GCs but is absent from the cell somata of these neurons (Figs. 3, 5). If chloride concentrations can be selectively lowered in the dendritic versus somatic regions of these cells, this suggests that GABA could exert a hyperpolarization in the region of high KCC2 expression and a depolarization in other regions. Such a dual effect of GABA is observed in hippocampal pyramidal neurons and has been hypothesized to result from differences in internal chloride concentrations within these neurons (Alger and Nicoll, 1979; Muller et al., 1989; for alternative explanation, see Staley et al., 1995). Further studies of KCC2 localization in pyramidal cells and focal applications of GABA in HCs and GCs would reveal whether the notion of differential chloride concentrations within individual cells has any merit.

\section{Developmental expression of $\mathrm{KCC} 2$ in the retina}

KCC2 expression is barely detectable at birth and follows a gradual time course of upregulation in the retina that is similar to that observed in the hippocampus, cerebellum, and spinal cord (Sharp et al., 1998; Rivera et al., 1999). In the hippocampus, the temporal expression of KCC2 is necessary and sufficient to reduce the reversal potential for GABA-mediated responses below the resting potential in CA3 neurons (Rivera et al., 1999). Here we find that the age-related increased expression of KCC2 correlates with the transition of GABA-mediated responses in the retina as well. In early postnatal retinas GABA is excitatory, whereas later GABA acts as an inhibitory neurotransmitter. For example, in P2-P5 mouse retinas, GABA increased the rate of spontaneous synaptic events in GCs (Bahring et al., 1994). In P0-P11 ferret retinas, GABA raised $\left[\mathrm{Ca}^{2+}\right]_{\mathrm{i}}$, and GABA antagonists reduced the spontaneous activity in GCs in ferret (Fischer et al., 1998); however, after P15, GABA no longer elevated $\left[\mathrm{Ca}^{2+}\right] \mathrm{i}$, and it suppressed spontaneous activity in GCs. Also, in neonatal rabbit retinas $(\mathrm{P} 0-\mathrm{P} 7)$, GABA-induced $\left[\mathrm{Ca}^{2+}\right]_{\mathrm{i}}$ increases were observed in all layers of the retina (Huang and Redburn, 1996).

Fischer et al. (1998) speculated that expression of an inwardly directed chloride transporter in early postnatal retinal cells raised $\left[\mathrm{Cl}^{-}\right]_{\mathrm{i}}$ to generate depolarizing responses to GABA. Sodiumdependent chloride cotransport is thought to be responsible for GABA-mediated depolarization in Rohon-Beard neurons, and upregulation of an isoform of the $\mathrm{Na}-\mathrm{K}-\mathrm{Cl}$ cotransporter supports this idea (Rohrbough and Spitzer, 1996; Plotkin et al.,
1997); however, a mechanism is necessary by which to actively lower $\left[\mathrm{Cl}^{-}\right]_{\mathrm{i}}$ in older neurons. We propose that upregulation of $\mathrm{KCC} 2$ provides a chloride extrusion mechanism in GCs to lower $E_{\mathrm{Cl}}$ adequately to produce GABA-mediated hyperpolarizing responses.

Interestingly, KCC2 expression was delayed in the OPL compared with the IPL. In HCs GABA is transiently upregulated in the rat between P6 and P16 (Fletcher and Kalloniatis, 1997). Because of the comparatively reduced expression of $\mathrm{KCC} 2$ in the OPL and the immediate availability of GABA, it is an appealing notion that the delayed expression of KCC2 in the OPL serves to facilitate synaptogenesis between BPCs and amacrine cells and GCs. In mouse, ribbon synapses in bipolar cell terminals begin appearing after P10, and the rate declines dramatically after eye opening (P14) (Fisher, 1979). Thus GABA would activate voltage-dependent $\mathrm{Ca}^{2+}$ channels in bipolar cells that, in turn, would enhance synaptic transmitter release from their terminals, serving as a requisite for synaptogenesis in many systems.

\section{REFERENCES}

Alger BE, Nicoll RA (1979) GABA-mediated biphasic inhibitory responses in hippocampus. Nature 281:315-317.

Alvarez-Leefmans FJ (1990) Intracellular $\mathrm{Cl}^{-}$regulation and synaptic inhibition in vertebrate and invertebrate neurons. In: Chloride channels and carriers in nerve, muscle, and glial cells (Alvarez-Leefmans FJ, Russell JM, eds), pp 109-158. New York: Plenum.

Bahring R, Standhardt H, Martelli EA, Grantyn R (1994) GABAactivated chloride currents of postnatal mouse retinal ganglion cells are blocked by acetylcholine and acetylcarnitine: how specific are ion channels in immature neurons? Eur J Neurosci 6:1089-1099.

Barnstable CJ, Drager UC (1984) Thy-1: a ganglion cell specific marker in rodent retina. Neuroscience 11:847-855.

Barres B, Silverstein BE, Corey DP, Chun LLY (1988) Immunological, morphological, and electrophysiological variation among retinal ganglion cells purified by panning. Neuron 1:791-803.

Blanco R, Vaquero CF, de la Villa P (1996) The effects of GABA and glycine on horizontal cells of the rabbit retina. Vision Res 24:3987-3995.

Buckley K, Kelly RB (1985) Identification of a transmembrane glycoprotein specific for secretory vesicles of neural and endocrine cells. J Cell Biol 100:1284-1294.

Cherubini E, Gaiarsa JL, Ben-Ari Y (1991) GABA: an excitatory transmitter in early postnatal life. Trends Neurosci 14:515-519.

Euler T, Wässle H Immunocytochemical identification of cone bipolar cells in the rat retina. J Comp Neurol 361:461-478.

Euler T, Schneider H, Wässle H (1996) Glutamate responses of bipolar cells in a slice preparation of the rat retina. J Neurosci 16:2934-2944.

Fischer KF, Lukasiewicz PD, Wong ROL (1998) Age-dependent and cell class-specific modulation of retinal ganglion cell bursting activity by GABA. J Neurosci 18:3767-3778.

Fisher LJ (1979) Development of synaptic arrays in the inner plexiform layer of neonatal mouse retina. J Comp Neurol 187:359-372.

Fletcher EL, Kalloniatis M (1997) Localization of amino acid neurotransmitters during postnatal development of the rat retina. J Comp Neurol 380:449-471.

Frumkes TE, Nelson R (1995) Functional role of GABA in cat retina. I.

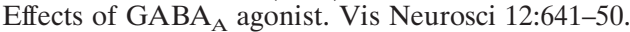

Gillen C, Brill S, Payne JA, Forbush III B (1996) Molecular cloning and functional expression of the $\mathrm{K}-\mathrm{Cl}$ cotransporter from rabbit, rat, and human. A new member of the cation-chloride cotransporter family. J Biol Chem 271:16237-16244.

Greferath U, Grunert U, Fritschy JM, Stephenson A, Mohler H, Wässle $\mathrm{H}$ (1995) $\mathrm{GABA}_{\mathrm{A}}$ receptor subunits have differential distributions in the rat retina: in situ hybridization and immunohistochemistry. J Comp Neurol 353:553-571.

Hiki K, D'Andrea RJ, Furze J, Crawford J, Woollatt E, Sutherland GR, Vadas MA, Gamble JR (1999) Cloning, characterization, and chromosomal location of a novel human $\mathrm{K}+-\mathrm{Cl}-$ cotransporter. J Biol Chem 274:10661-10667.

Huang B, Redburn D (1996) GABA-induced increases in $\left[\mathrm{Ca}^{2+}\right]$ in retinal neurons of postnatal rabbits. Vis Neurosci 13:441-447. 
Koulen P, Sassoe-Pognetto M, Grunert U, Wässle H (1996) Selective clustering of $\mathrm{GABA}_{\mathrm{A}}$ and glycine receptors in the mammalian retina. J Neurosci 16:2127-2140.

Koulen P, Fletcher EL, Craven S, Bredt DS, Wässle H (1998) Immunocytochemical localization of the postsynaptic density protein PSD-95 in the mammalian retina. J Neurosci 18:10136-10149.

Liu CJ, Chaturvedi N, Barnstable CJ, Dreyer EB (1996) Retinal Thy-1 expression during development. Invest Ophthalmol Vis Sci 37:1469-1473.

Luhmann HJ, Prince DA (1991) Postnatal maturation of the GABAergic system in rat neocortex. J Neurophysiol 65:247-263.

Mount DB, Mercado A, Song L, Xu J, George Jr AL, Delpire E, Gamba G (1999) Cloning and characterization of KCC3 and KCC4, new members of the cation-chloride cotransporter gene family. J Biol Chem 274:16355-16362.

Muller W, Misgeld U, Lux HD (1989) gamma-Aminobutyric acidinduced ion movements in the guinea pig hippocampal slice. Brain Res 484:184-191.

Owens DF, Boyce LH, Davis MBE, Kriegstein AR (1996) Excitatory GABA responses in embryonic and neonatal cortical slices demonstrated by gramicidin perforated-patch recordings and calcium imaging. J Neurosci 16:6414-6423.

Pasteels B, Rogers J, Blachier F, Pochet R (1990) Calbindin and calretinin localization in retina from different species. Vis Neurosci 5:1-16.

Payne J, Stevenson J, Donaldson L (1996) Molecular characterization of a putative $\mathrm{K}-\mathrm{Cl}$ cotransporter in rat brain: a neuronal-specific isoform. J Biol Chem 271:16245-16252.

Payne JA (1997) Functional characterization of the neuronal-specific $\mathrm{K}-\mathrm{Cl}$ cotransporter: implications for $\left[\mathrm{K}^{+}\right]_{\mathrm{o}}$ regulation. Am J Physiol 42:C1516-C1525.

Peichl L, Gonzaalez-Soriano J (1994) Morphological types of horizontal cell in rodent retinae: a comparison of rat, mouse, gerbil, and guinea pig. Vis Neurosci 11:501-517.

Perry VH, Walker M (1980) Amacrine cells, displaced amacrine cells and interplexiform cells in the retina of the rat. Proc R Soc Lond [Biol] 208:415-431.

Plotkin MD, Snyder EY, Hebert SC, Delpire E (1997) Expression of the $\mathrm{Na}-\mathrm{K}-2 \mathrm{Cl}$ cotransporter is developmentally regulated in postnatal rat brains: a possible mechanism underlying GABA's excitatory role in immature brain. J Neurobiol 33:781-795.

Rich KA, Zhan Y, Blanks JC (1997) Migration and synaptogenesis of cone photoreceptors in the developing mouse retina. J Comp Neurol 388:47-63.

Rivera C, Voipio J, Payne JA, Ruusuvuori E, Lahtinen H, Lamsa K, Pirvola U, Saarma M, Kaila K (1999) The K-Cl cotransporter KCC2 renders GABA hyperpolarizing during neuronal maturation. Nature 397:251-255.

Rohrbough J, Spitzer NC (1996) Regulation of intracellular Cl- levels by $\mathrm{Na}^{+}$-dependent $\mathrm{Cl}^{-}$cotransport distinguishes depolarizing from hyperpolarizing $\mathrm{GABA}_{\mathrm{A}}$ receptor-mediated responses in spinal neurons. J Neurosci 16:82-91.

Sassoè-Pognetto M, Wässle H, Grunert U (1994) Glycinergic synapses in the rod pathway of the rat retina: cone bipolar cells express the $\alpha 1$ subunit of the glycine receptor. J Neurosci 14:5131-5146.

Schmid S, Guenther E, Kohler K (1995) Changes in Thy-1 antigen immunoreactivity in the rat retina during pre- and postnatal development. Neurosci Lett 199:91-94.

Sharp JW, Williams JR, Payne JA (1998) Developmental expression of cation chloride cotransporters in rat brain. Soc Neurosci Abstr 24:1830-1831.

Staley KJ, Soldo BL, Proctor WR (1995) Ionic mechanisms of neuronal excitation by inhibitory GABAA receptors. Science 269:977-981.

Taschenberger H, Grantyn R (1995) Several types of Ca2+ channels mediate glutamatergic synaptic responses to activation of single Thy-1-immunolabeled rat retinal ganglion neurons. J Neurosci 15: $2240-2254$

Thompson SM, Gahwiler BH (1989) Activity-dependent disinhibition. II. Effects of extracellular potassium, furosemide, and membrane potential on $\mathrm{E}_{\mathrm{Cl}-}$ in hippocampal CA3 neurons. J Neurophysiol 61:512-522.

Thompson SM, Deisz RA, Prince DA (1988) Relative contributions of passive equilibrium and active transport to the distribution of chloride in mammalian cortical neurons. J Neurophysiol 60:105-124.

Vardi N, Masarachia P, Sterling P (1992) Immunoreactivity to GABA receptor in the outer plexiform layer of the cat retina. J Comp Neurol 320:394-397.

Wässle H, Yamashita M, Greferath U, Grunert U, Muller F (1991) The rod bipolar cell of the mammalian retina. Vis Neurosci 7:99-112.

Wässle H, Koulen P, Brandstatter JH, Fletcher EL, Becker CM (1998) Glycine and GABA receptors in the mammalian retina. Vision Res 38:1411-1430.

Williams JR, Sharp JW, Kumari VG, Wilson M, Payne JA (1999) The neuron-specific $\mathrm{K}-\mathrm{Cl}$ cotransporter, $\mathrm{KCC} 2$ : antibody development and initial characterization of the protein. J Biol Chem 274:12656-12664.

Yuste R, Katz LC (1991) Control of postsynaptic $\mathrm{Ca}^{2+}$ influx in developing neocortex by excitatory and inhibitory neurotransmitters. Neuron 6:333-344.

Zhang L, Spigelman I, Carlen PL (1991) Development of GABAmediated, chloride-dependent inhibition in CA1 pyramidal neurons of immature rat hippocampal slices. J Physiol (Lond) 444:25-49. 